\title{
LIMB-SHAKING SEBAGAI MANIFESTASI YANG JARANG DARI TRANSIENT ISCHEMIC ATTACK AKIBAT STENOSIS BERAT ARTERI KAROTIS
}

\author{
LIMB-SHAKING AS A RARE MANIFESTATION OF TRANSIENT ISCHEMIC \\ ATTACK ASSOCIATED WITH SEVERE CAROTID ARTERI STENOSIS
}

Kumara Tini*

\begin{abstract}
Limb-shaking is a rare manifestation of Transient Ischemic Attack (TIA), commonly occurs when a severe carotid stenosis causes a cerebral hypoperfusion. Male 53 years of age experienced repeated limb-shaking within a week of left hand and arm accompanied by a vision of light sparks. Brain Magnetic Resonance Imaging (MRI) and Magentic Resonace Angiography (MRA) showed chronic watershed infarct at right fronto-parietal lobes and 80-90\% severe stenosis of right internal carotid artery with digital subtraction angiography (DSA) showed 70\% stenosis at the same site. Carotid Artery and Stenting (CAS) was done a week after and symptoms disappeared subsequently. Recognizing this rare symptom of severe carotid stenosis is very important since appropriate management can minimized the risk of future stroke.
\end{abstract}

Keyword: Carotid stenosis, Limb-shaking, TIA

\section{ABSTRAK}

Limb-shaking adalah manifestasi yang jarang dari transient ischemic attack (TIA), biasanya terjadi akibat hipoperfusi serebri pada stenosis berat arteri karotis. Laki-laki 53 tahun mengalami limb-shaking berulang dalam seminggu pada lengan dan tangan kiri disertai melihat percikan sinar. Magnetic resonance imaging (MRI) dan magnetic resonance agiography (MRA) kepala menunjukkan infark di area watershed lobus fronto-parietal kanan dan stenosis $80-90 \%$ di arteri karotis interna kanan, serta digital substraction angiography (DSA) menunjukkan stenosis 70\% pada lokasi yang sama. Keluhan hilang setelah pasien dilakukan tindakan revaskularisasi carotid artery and stenting (CAS) seminggu kemudian. Pengenalan gejala yang jarang dari stenosis berat arteri karotis ini sangat penting, karena dengan penanganan yang tepat dapat mengurangi terjadinya stroke.

Kata kunci: Limb-shaking, stenosis karotis, TIA

*Bagian/SMF Neurologi FK Universitas Udayana Denpasar, Bali. Korespondensi: kumaratini@yahoo.co.id.

\section{PENDAHULUAN}

Transient ischemic attack (TIA) memiliki gejala berupa defisit neurologis, seperti kelumpuhan, penurunan sensibilitas, atau defisit lainnya. Salah satu manifestasi yang jarang adalah limb-shaking, suatu gerakan singkat dan menghentak-hentak dari kaki dan/ataupun lengan dan sering kali dirancukan dengan bangkitan ataupun gangguan gerak involunter. ${ }^{1}$ Kasus ini seringkali dikaitkan dengan stenosis berat pada arteri karotis interna (internal carotid artery/ ICA) dan jarang pada arteri serebri anterior (anterior cerebri artery/ACA) ataupun arteri serebri media (media cerebri artery/MCA).

Peristiwa ini dicetuskan akibat terjadinya penurunan perfusi serebri akibat stenosis berat pada arteri karotis. Gejala yang berbeda ini merupakan tanda penting pada TIA, karena dapat merupakan indikator terjadinya stenosis berat arteri karotis dan pasien sangat berisiko untuk mengalami stroke, seperti pada laporan kasus berikut yang gejalanya menghilang dengan tindakan revaskularisasi arteri karotis dengan carotid artery stenting (CAS). ${ }^{2}$

\section{KASUS}

Pasien seorang laki-laki berusia 53 tahun, mengeluh lengan dan tangan kiri menghentakhentak (limb shaking) sendirinya saat bangun dari posisi tidur di pagi hari, berlangsung hanya beberapa detik dan kejadian serupa berulang 3 kali dalam seminggu. Pasien juga seperti melihat percikanpercikan sinar pada mata kanan yang menghilang dalam beberapa menit. Saat kejadian ketiga, keluhan disertai kelemahan minimal pada tangan kiri yang kembali normal dalam 5 menit.

Pasien adalah penderita diabetes melitus (DM) tipe II, hipertensi, dan dislipidemia dengan terapi metformin $850 \mathrm{mg}$, irbesartan $150 \mathrm{mg}$, atorvastatin 
20mg, dan asetosal 100mg. Pada pemeriksaan fisik didapatkan tekanan darah $150 / 90 \mathrm{mmHg}$ dan tanda vital lain dalam batas normal. Tidak ditemukan bruit karotis bilateral dan pemeriksaan neurologis dalam batas normal. Hasil laboratorium berupa HDL rendah $(28 \mathrm{mg} / \mathrm{dL})$ dan hipertrigiseridemia $(466 \mathrm{mg} / \mathrm{dL})$.

Pemeriksaan CT scan kepala tanpa kontras tidak menunjukkan tanda infark akut. Magnetic resonance imaging (MRI) kepala memberikan gambaran infark akut pada fitur FLAIR (fluid attenuation inversion recovery) di daerah subkorteks (watershed zone) kanan dan chronic small vessels changes pada substansia alba lobus fronto-parietal kanan, fitur DWI (diffuse weight imaging) tidak menunjukkan gambaran infark (Gambar 1).

Magnetic resonance angiography (MRA) menunjukkan adanya stenosis di arteri karotis interna kanan 80-90\% (Gambar 2), sedangkan sirkulasi intrakranial normal (Gambar 3). Angiografi dengan digital substraction angiography (DSA) dikerjakan segera dan memberikan gambaran stenosis arteri karotis kanan sebesar $70 \%$ pada distal bifurkasio arteri karotis.

Seminggu setelah pemberian antiplatelet ganda (asetosal 100mg dan klopidogrel $75 \mathrm{mg}$ ) dilakukan tindakan revaskularisasi arteri karotis interna kanan dengan CAS (Gambar 4). Pasien diobservasi 3 hari kemudian dievaluasi ulang secara klinis seminggu dan setiap bulannya selama setahun, tidak terdapat keluhan. CT angiography (CTA) kontrol dikerjakan 1 tahun setelah terapi, menunjukkan patensi arteri karotis interna bilateral. Terapi antiplatelet ganda diberikan selama 3 bulan, dilanjutkan asetosal tunggal seterusnya.

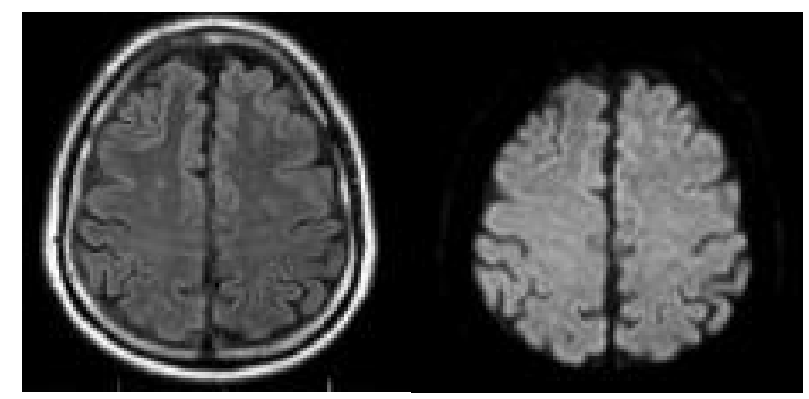

Gambar 1. Gambaran MRI Fitur FLAIR (kiri) dan DWI (kanan)

Tampak gambaran infark subkortikal di frontal-parietal kanan pada FLAIR, DWI tidak ditemukan gambaran infark pada DWI.

\section{PEMBAHASAN}

Episode limb-shaking akibat stenosis arteri karotis pertama kali dilaporkan oleh Miller Fisher pada tahun 1962. ${ }^{3}$ Gejalanya berupa gerakan hiperkinesia involunter baik ritmis ataupun non-ritmis yang oleh pasien disebutkan sebagai menghentak-hentak, bergetar, atau tremor melibatkan tangan, lengan, kaki, atau keduanya secara unilateral tanpa melibatkan wajah. Pasien ini mengalami gejala yang sama pada tangan kirinya diikuti gejala penyerta berupa melihat percikan-percikan sinar dan kelemahan tangan kiri sesaat. Gejala yang muncul mendadak dengan perbaikan segera itulah yang menyebabkan kecurigaan TIA, disertai adanya faktor risiko vaskular pada pasien, seperti hipertensi, DM tipe II, dan dislipidemia. ${ }^{4}$

Pasien mengalami serangan berulang saat pagi hari, saat bangun dari posisi tidur. Limb-shaking TIA sering kali dihubungkan dengan hipotensi ortostatik pada pasien dengan stenosis berat arteri karotis dan membaik apabila pasien duduk atau berbaring, menunjukkan hipoperfusi sebagai pencetus gejala. Hipoperfusi serebral telah lama dianggap sebagai patofisiologi limb-shaking TIA. Suatu studi menjelaskan bahwa pasien dengan stenosis karotis dan episode limb-shaking menunjukkan berkurangnya sirkulasi pada daerah perbatasan ACA dan MCA. ${ }^{5}$ Hal ini menjelaskan gejala limb-shaking tidak pernah melibatkan wajah, sesuai dengan teritori perbatasan secara homunkulus motorik. ${ }^{6}$ Studi dari Bogousslavsky dan Regli yang melibatkan 51 pasien dengan infark di watershed area, 12\% mengalami episode limb-shaking. Adanya keterlibatan watershed area dapat menjelaskan limb-shaking lebih sering pada ekstremitas atas dan lebih jarang pada ekstremitas bawah yang merupakan teritori ACA. ${ }^{7}$

Mekanisme pasti yang menyebabkan terjadinya limb-shaking masih belum jelas, namun transient focal ischemia sampai saat ini dianggap sebagai penyebab utama. Galvez-Jimenes dkk menganggap limb-shaking sebagai salah satu manifestasi dari diskenesia sekunder atau simtomatik dengan etiologi vaskuler. ${ }^{8-9}$ Beberapa gangguan gerak hiperkinetik, seperti hemidistonia dan hemikorea dianggap bertanggung jawab terhadap terjadinya limb-shaking, namun gangguan gerak sendiri sangat jarang sebagai 


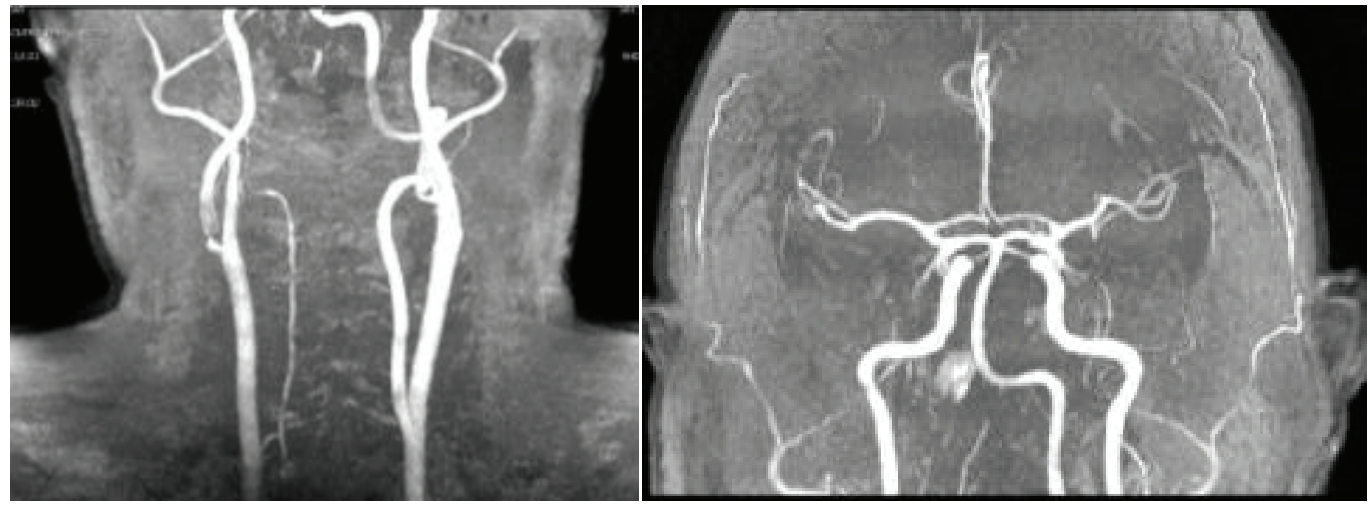

Gambar 2. Gambaran MRA

Tampak stenosis berat (80\%) pada arteri karotis interna kanan, distal dari bifurkasio karotis (kiri), sedangkan sirkulasi intrakranial tampak normal (kanan).

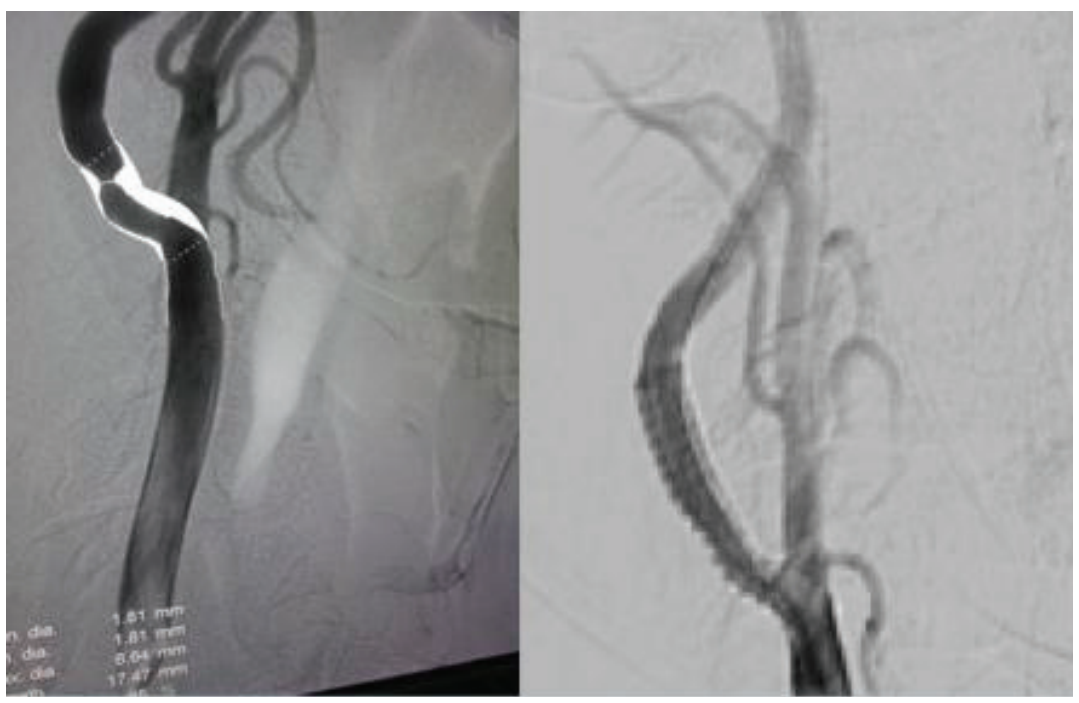

Gambar 4. Gambaran Digital Substraction Angiography (DSA) Pascatindakan Carotid Artery Stenting (CAS)

Gambar arteri karotis kanan sebelum dilakukan tindakan (kiri) dan setelah pemasangan sten tampak revaskularisasi dengan residual stenosis $\sim 30 \%$.

manifestasi stroke $(\sim 1 \%){ }^{10}$

Bangkitan epileptik dapat dibedakan dengan limb-shaking. Limb-shaking tidak menimbulkan penurunan kesadaran, dicetuskan pada kondisi tertentu yang menimbulkan gangguan aliran darah serebral seperti bangun dari posisi tidur, tidak ditemukan bangkitan tonik dan jarang melibatkan wajah dan badan. ${ }^{9}$ Pasien ini tidak dilakukan pemeriksaan elektroensefalografi (EEG), namun pada beberapa studi gagal ditemukan gelombang yang berkaitan dengan limb-shaking, walau pada beberapa pasien ditemukan adanya gelombang lambat. ${ }^{11}$

Hal yang paling penting dari limb-shaking ini adalah adanya suatu stenosis berat dari arteri karotis yang memerlukan suatu pemeriksaan dan tindakan definitif untuk mencegah pasien mengalami stroke hebat. Pada pasien ini tidak ditemukan bruit arteri karotis, namun pada MRA ditemukan adanya stenosis $80-90 \%$ arteri karotis interna kanan dengan gambaran infark di teritori water shed. Pemeriksaan lanjutan dengan DSA menunjukkan adanya stenosis $70 \%$ pada arteri karotis interna kanan. ${ }^{12}$

Manajemen dari TIA akibat hipoperfusi adalah meningkatkan kembali aliran darah serebri dengan kontrol seksama dari tekanan darah disertai revaskularisasi secara pembedahan dan non-pembedahan. Beberapa kasus menunjukkan perbaikan dengan meningkatkan tekanan darah, namun pada 
keadaan dengan gangguan jantung dan ginjal tindakan ini dapat berbahaya. Pasien dengan stenosis karotis interna, tindakan pilihan revaskularisasi adalah berupa CAS ataupun carotid enarterectomy (CEA) untuk mengatasi gejala dan mencegah kejadian stroke. Adapun pada oklusi total arteri karotis, tindakan bypass karotis eksterna-karotis interna (EC-IC by-pass) bisa menjadi pilihan. ${ }^{12-13}$

\section{KESIMPULAN}

Limb-shaking sebagai manifestasi TIA pada stenosis arteri karotis sangat perlu dikenali agar segera dilakukan tindakan prevensi sekunder definitif untuk memperbaiki vaskularisasi menghilangkan gejala dan yang terpenting mencegah terjadinya TIA/ stroke berulang.

\section{DAFTAR PUSTAKA}

1. Kouvelos GN, Nassis C, Papa N, Padopoulos G, Matsagkas MI. Limb-shaking transient ischemic attacks successfully treated with external carotid artery stenting. Medicine. 2012.

2. Turtszo LC, Gailloud P, Gottesman RE. Treatment of limb-shaking TIAs with external carotid artery stenting. Clin Neurol Neurosurg. 2009;111(8):695-8.

3. Fisher CM. Concerning recurrent transient cerebral ischemic attacks. Can Med. 1962;86(24):1091-9.

4. Yanagihara T, Piepgras DG, Klass DW. Repetitive involuntary movement associated with episodic cerebral ischemia. Ann Neurol. 1985;18(2):244-50.
5. Kiechl S, Furtner M, Knoflach M, Werner P. Willeit J. Kaleidoscopic vision and jerking leg on the ski slope. Lancet. 2007:370(9602):1878.

6. Yamauchi H, Kudoh T, Sugimoto K, Takahashi M, Kishibe Y, Okazawa H. Pattern of collaterals, type of infarcts, and haemodynaic impairment in carotid artery occlusion. J Neurol Neurosurg. 2004:75(12):1697-701

7. Bogousslavsky J, Regli F. Unilateral watershed cerebral infarcts. Neurology. 1985;36(3):373-7.

8. Galvez-Jimenez N, Hanson MR, Hangreave MJ, Peirut. Transient ischemic attacks and paroxysmal dyskinesia: an under-recognized association. Adv Neurol. 2002:89:421-32.

9. Yoon YS, Kim JS. Limb-shaking TIA: an asterixis. American Academy of Neurol. 2013:81(10):1-5.

10. Persoon S, Kappelle LJ, Klijn CJ. Limb-shaking transient ischaemic attacks in patients with internal carotid artery occlusion: a case-control study. Brain. 2010:133(3):915-22.

11. Ali S, Khan MA, Khaelani B. Limb-shaking ischemic attacks: case report. BMJ Neurol. 2006;6(1):1-5.

12. Baquis GD, Pessin MS, Scott R. Limb-shaking a carotid TIA. Stroke. 1985;16(3):444-8.

13. Xu DS, Abruzzo TA, Albuquerque FC. External carotid artery stenting to treat patients with symptomatic ipsilateral carotid artery occlusion: a multicenter case series. Neurosurgery. 2010:67(2):314-21. 